\title{
Use of Temperature Sensors in Testing Soil Humus Content in Saline Wetland in Response to Freeze-Thaw Cycles
}

\author{
Qian Liu, ${ }^{1,2}$ Jie Tang, ${ }^{1 *}$ Cheng-shuai $\mathrm{He}^{2}$, and Christopher Chun Ki Chan ${ }^{3 * *}$ \\ ${ }^{1}$ College of New Energy and Environment, Jilin University, Changchun 130012, China \\ ${ }^{2}$ College of Landscape Architecture, Changchun University, Changchun 130012, China \\ ${ }^{3}$ Department of Information Management, Chaoyang University of Technology, Taichung 413310, Taiwan
}

(Received April 22, 2020; accepted August 18, 2020)

Keywords: humus carbon, fulvic acid, humic acid, humin, saline wetland, unfreezing

As a stable substance in soil organic matter, soil humus can not only change the physical and chemical properties of soil, such as soil fertility, air permeability, and adsorption, but also affect the number of microorganisms in the soil. Soil humus is an important indicator of soil fertility. The freeze-thaw effect is widely distributed in north and northeast China. Under the effect of alternate freeze-thaw cycles, a series of changes in the content of soil humus occur. In this study, humus-related components, such as humus carbon (HE), humic acid (HA), fulvic acid (FA), and humin (HM), were studied. The effect of freeze-thaw cycles on the soil fertility of saline wetland was investigated. Our paper provides data for the evaluation of the soil nutrient status in saline wetland. In response to the environmental policy of controlling soil desertification, people should improve the control technology of soil desertification in saline wetland and implement sustainable development strategies.

\section{Introduction}

The global carbon and oxygen balance has been seriously affected by increasing greenhouse gas emissions from industrial production and waste emissions from the use of fossil fuels (e.g., combustion engines). Habitat and environment sustainability have been challenged like never before, with carbon dioxide increases causing polar ice to melt. ${ }^{(1)}$ In the cold temperate zone of northeast China, the soil often experiences a freeze-thaw phenomenon in early spring. ${ }^{(2)}$ Climate change has affected the occurrence of soil freeze-thaw events. ${ }^{(3,4)}$ The effect of freeze-thaw is very significant in the global carbon cycle, and research on the soil carbon balance, such as soil humus, has attracted increasing attention by scientists worldwide. Soil humus can change soil permeability, soil adsorption, and other physicochemical properties, and is an important indicator of soil fertility. ${ }^{(5)}$ Owing to the colloidal properties of humus, which can adsorb a large number of metal ions and toxic organic substances, the study of humus is of great significance for environmental protection and pollutant control, and especially for preventing soil desertification. ${ }^{(6,7)}$ Soil humus can form a stable relation with pollutants. ${ }^{(8)}$

\footnotetext{
*Corresponding author: e-mail: tangjie0724@126.com

** Corresponding author: e-mail: christopher.c.chan@ryerson.ca https://doi.org/10.18494/SAM.2020.2930
} 
In a natural environment, soil humus is closely related to the formation of soil, and the water retention of soil is closely related to humus. ${ }^{(9)}$ Freeze-thaw is one of the climatic features of northeast China. Our research is focused on the consequences of the effect of freeze-thaw on wetland soil salinity and its profile characteristics. By understanding the effect of freeze-thaw and its effect on wetland soil salinity, people can understand the status of saline wetland soil nutrients, raise awareness about the protection of wetland environment systems, and prevent saline wetland soil desertification. The content of soil humus in saline wetland can be used as an index to measure the environmental pollution in an area. Under the premise of climate change, the study of the change of soil humus in saline wetland under the effect of freeze-thaw can also provide the groundwork for an experimental study on the carbon cycle in the atmosphere.

The freeze-thaw effect is a common physical phenomenon in nature and warrants significant practical research. Whenever the temperature drops below the freezing point of water, the water in soil freezes, but it also melts as the temperature rises. ${ }^{(10)}$ The freeze-thaw process plays a very important role in the natural ecosystem, promoting the formation of soil and increasing soil fertility. Freeze-thaw accelerates the decomposition of organic matter in soil and provides nutrients for plants. ${ }^{(11-13)}$ In addition, the thawing process can increase the microbial respiration rate and the concentrations of nitrogen, phosphorus, and potassium in soil; ${ }^{(14-16)}$ these changes improve the ecosystem and microbial community structures and the activity of enzymes in soil. $^{(17,18)}$ At present, most studies mainly focus on the effect of freeze-thaw in soil on active organic carbon during freezing temperatures ${ }^{(19,20)}$ and there has been little examination of the effect of soil humus after freeze-thaw. Therefore, in this paper, we address this gap by exploring the effect of freeze-thaw on soil humus in saline wetland (specifically, the Chagan Lake reed wetland in Songyuan City, Jilin Province), from which we obtain data and evaluate saline wetland soil nutrients. The freeze-thaw temperature has been difficult to accurately monitor at all times; therefore, we hope to monitor freeze-thaw cycles in a way to improve temperature sensors in order to collect more accurate data.

\section{Materials and Methods}

\subsection{Overview of study area}

Chagan Lake, Songyuan City, Jilin Province, is located in the Songnen plain. It is a wetland and its ecosystem is well maintained, with abundant water resources. It is located between $124^{\circ} 03^{\prime}$ ' and $124^{\circ} 34^{\prime}$ ' east and between $45^{\circ} 08^{\prime}$ and $45^{\circ} 35^{\prime}$ north. The annual average temperature is around $4.5^{\circ} \mathrm{C} .{ }^{(21)}$ It has a temperate continental monsoon climate. The soil in the study area is mainly saline alkali soil, which is very fertile and conducive to the growth of various crops. Chagan Lake has been listed as a national nature reserve, the topsoil layer is well protected, and saline wetland soil is dominant in this region. The soil in the whole area is subject to freeze-thaw every year, making it ideal for obtaining freeze-thaw soil samples. The soil properties are also relatively stable. ${ }^{(22)}$ 


\subsection{Soil sample collection and processing}

Sampling place: Wetland soil of Chagan Lake, Qianguo County, Songyuan City, Jilin Province.

Sampling requirements: The appropriate sampling route and method were determined according to the shape and size of the specific sampling plot on the premise of ensuring a uniform distribution of sample points and reducing the walking distance.

Sampling method: The "S" shape sampling method was adopted to uniformly collect soil of the same type at nine sample points in five different sections of depths of $0-10,10-20,20-30$, $30-40$, and $40-50 \mathrm{~cm}$. The soil samples were from the same layer, and each sample was stored in small bags (fresh soil was kept at $4{ }^{\circ} \mathrm{C}$ and dry soil was kept at room temperature) until measurement.

Sample processing: Each soil sample was filtered through a $0.25 \mathrm{~mm}$ sieve.

Sample collection locations are shown in Fig. 1.

\subsection{Experimental design}

The tests were carried out indoors and test soil samples were divided into two groups. Using a temperature sensor, we determined the freeze-thaw temperature, monitoring all events in real time (Fig. 2). Freeze-thaw cycles were performed at $-5-5{ }^{\circ} \mathrm{C}$ and $-25-5{ }^{\circ} \mathrm{C}$ with two gradients, i.e., the sample was frozen at -5 or $-25{ }^{\circ} \mathrm{C}$ and cultured for $24 \mathrm{~h}$, and then thawed at $5{ }^{\circ} \mathrm{C}$ and cultured for $24 \mathrm{~h}$; this process is a freeze-thaw cycle. Samples were freeze-thawed 0, 1, 3, 5 or 7 times (referred to as FT0, FT1, FT3, FT5, and FT7, respectively), and each soil sample underwent three repeated tests for accuracy. The experimental process is shown in Fig. 3.

\subsection{Determination of index and method}

For humus component extraction, $2.5 \mathrm{~g}$ of an air-dried soil sample was weighed in a $100 \mathrm{~mL}$ centrifuge tube, then $50 \mathrm{~mL}$ of a mixture of $0.1 \mathrm{~mol} \cdot \mathrm{L}^{-1} \mathrm{Na}_{4} \mathrm{P}_{2} \mathrm{O}_{7} \cdot 10 \mathrm{H}_{2} \mathrm{O}$ and $0.1 \mathrm{~mol} \cdot \mathrm{L}^{-1}$

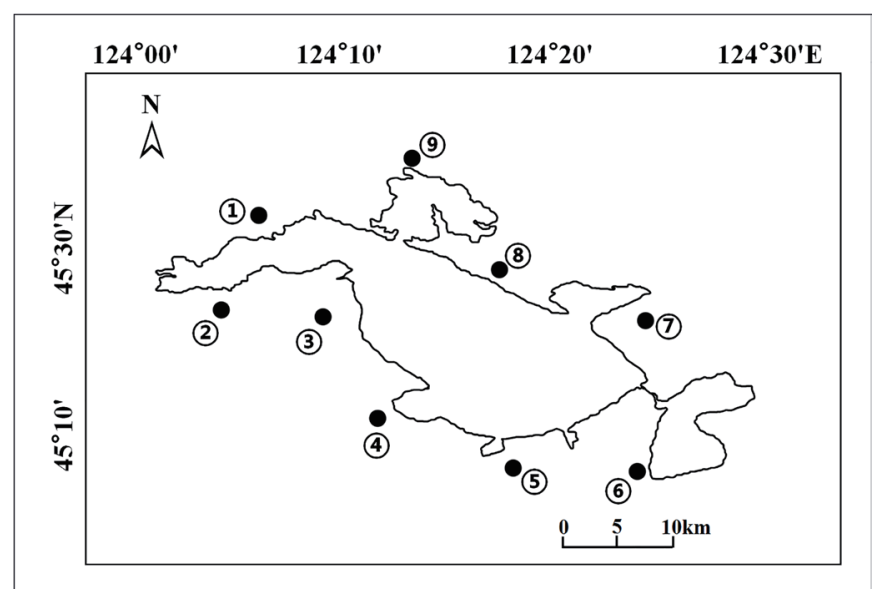

Fig. 1. Sample collection locations. 


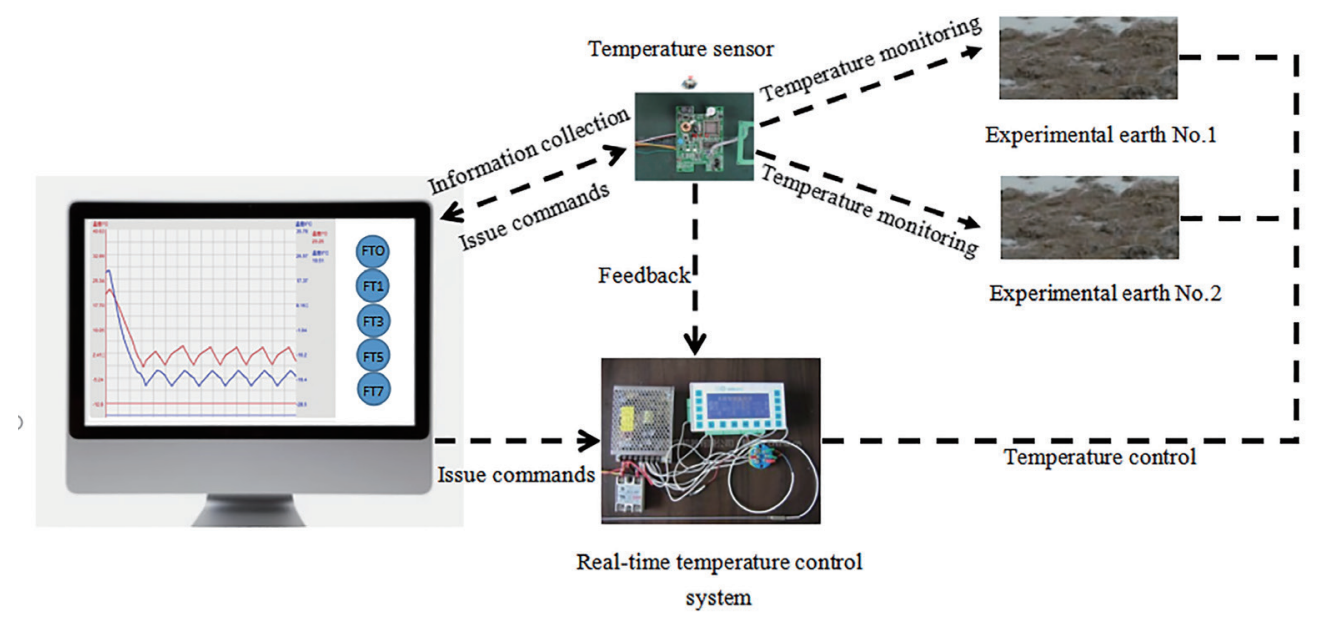

Fig. 2. (Color online) Temperature sensing system.
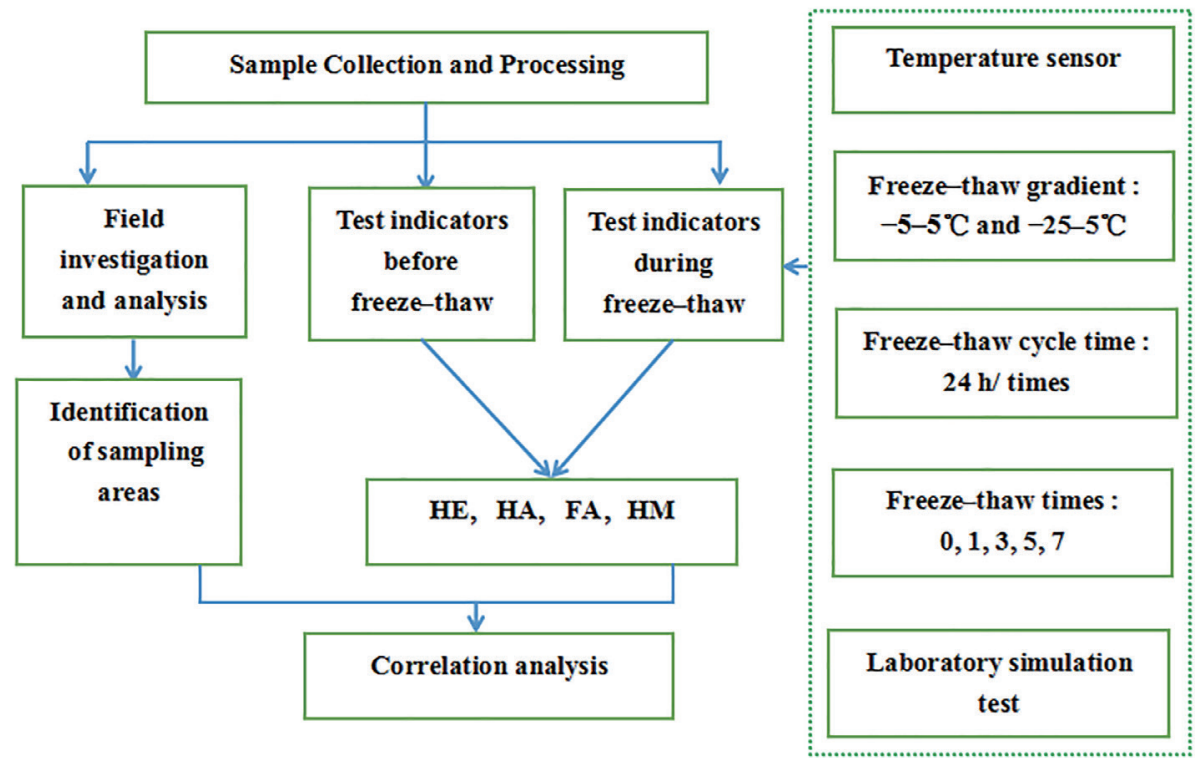

Fig. 3. (Color online) Experimental process.

$\mathrm{NaOH}$ was added to the above $100 \mathrm{~mL}$ centrifuge tube. The resulting mixture was centrifuged at $145 \mathrm{rpm}$ at $70 \pm 2{ }^{\circ} \mathrm{C}$ on a constant-temperature water bath oscillator. The experimental samples were soaked and extracted in the above liquid for $1 \mathrm{~h}$, then centrifuged and filtered. Subsequently, the supernatant was suctioned and the liquid was transferred to a $50 \mathrm{~mL}$ volumetric flask, then diluted to $50 \mathrm{~mL}$ with distilled water. The extract in the volumetric flask was the extractable humus carbon (HE), and the residue in the centrifuge tube was crude humin (HM). $30 \mathrm{~mL}$ of the above alkali extract was placed in a $50 \mathrm{~mL}$ triangular bottle and $1 \mathrm{~mol} \cdot \mathrm{L}^{-1}$ $\mathrm{H}_{2} \mathrm{SO}_{4}$ was added. The $\mathrm{pH}$ was adjusted to $1.0-1.5$. The solution was heated in a water bath at $60-70{ }^{\circ} \mathrm{C}$ for $1-2 \mathrm{~h}$ then left overnight. The next day, the solution was filtered with mediumspeed filter paper (quantitative), where the precipitate was humic acid (HA) and the solution was fulvic acid (FA). ${ }^{(23)}$ 


\subsection{Data analysis}

SPSS 24.0 and Microsoft Office Excel 2003 were used for data statistics, analysis, and mapping. The unitary linear regression model and Pearson correlation coefficient were used to analyze the relationship among the components, and the significance level was set at 0.05 .

\section{Results and Analysis}

The alternate freezing and thawing of soil can directly or indirectly affect its physical and chemical properties. ${ }^{(24,25)}$ Under the current climate change conditions, the effects of alternate freeze-thaw on the carbon storage cycle of soil and the material circulation of the ecosystem in permafrost areas have become a hot topic. ${ }^{(26-28)}$ By combining indoor freeze-thaw simulations with field observations, it has been found that different temperatures, rates, and cycles of freeze-thaw have different effects on organic carbon and microorganisms in soil. ${ }^{(29)}$ Freeze-thaw cycles increase soluble carbon loss, inhibit microbial growth, and reduce the rate of microbial carbon increase. ${ }^{(30)}$ The freeze-thaw process can improve the colloidal properties of soil and promote the production of soil nutrients. On the basis of the effects of active organic carbon on soil, soil respiration, and soil microbial characteristics, it is suggested that the relationships among global changes with regards to freeze-thaw, freeze-thaw soil fertility, and soil desertification should be studied in the future. ${ }^{(31,32)}$

\subsection{Effects of freeze-thaw temperature on soil humus and its components}

\subsubsection{Effect of freeze-thaw temperature on humus content in saline wetland soil}

The effect of the freeze-thaw temperature on the HE content in saline wetland soil is shown in Fig. 4. Under the conditions of freeze-thaw temperatures of $-5-5{ }^{\circ} \mathrm{C}$ and $-25-5{ }^{\circ} \mathrm{C}$, the change in $\mathrm{HE}$ content in the vertically distributed soil layers was analyzed, and the HE content was observed to be generally low. Under the freeze-thaw temperature cycle of $-25-5{ }^{\circ} \mathrm{C}$, the rate of change in $\mathrm{HE}$ content in the vertically distributed soil layers is higher than that under the freeze-thaw temperature cycle of $-5-5{ }^{\circ} \mathrm{C}$. This disparity may be caused by the death of soil microbes at low temperatures, which led to a decrease in HE content. Then, the cold-tolerant microorganisms adapted to the low-temperature environment, resulting in the HE content slowly increasing and leveling off. ${ }^{(33)}$

\subsubsection{Effect of freeze-thaw temperature on FA content in saline wetland soil}

From Fig. 5, the effect of the freeze-thaw temperature on the FA content in soil is unclear, which may be due to the stability of FA. ${ }^{(34)}$ Under the condition of one freeze-thaw cycle, the FA content in the alternate freeze-thaw at $-25-5^{\circ} \mathrm{C}$ is generally slightly higher than that in the alternate freeze-thaw at $-5-5{ }^{\circ} \mathrm{C}$. However, with increasing number of freeze-thaw cycles, the FA content decreased significantly at $-25-5{ }^{\circ} \mathrm{C}$. The FA content generally maintains a stable state and is almost unaffected by the freeze-thaw temperature. 

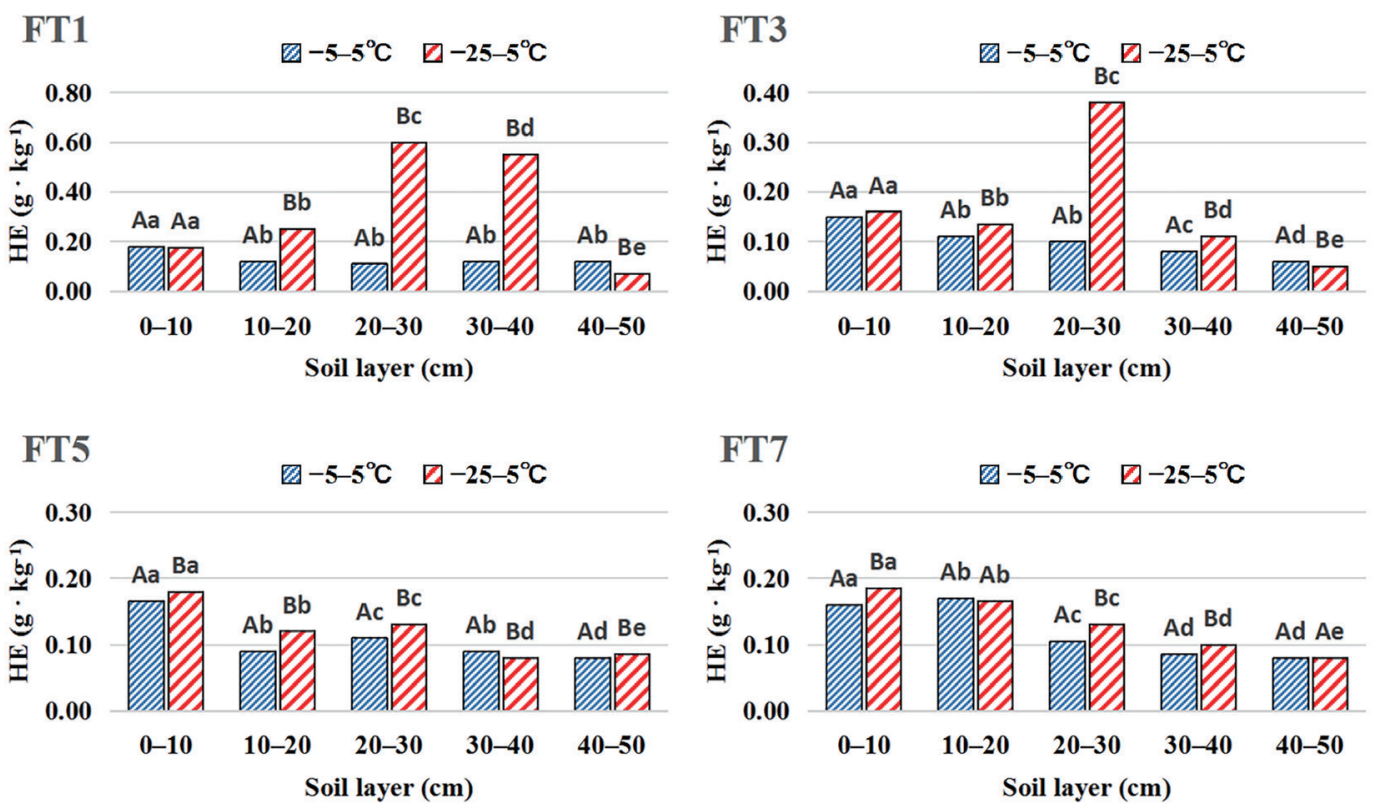

Fig. 4. (Color online) Effects of different freeze-thaw temperatures on HE content in saline wetland soil.
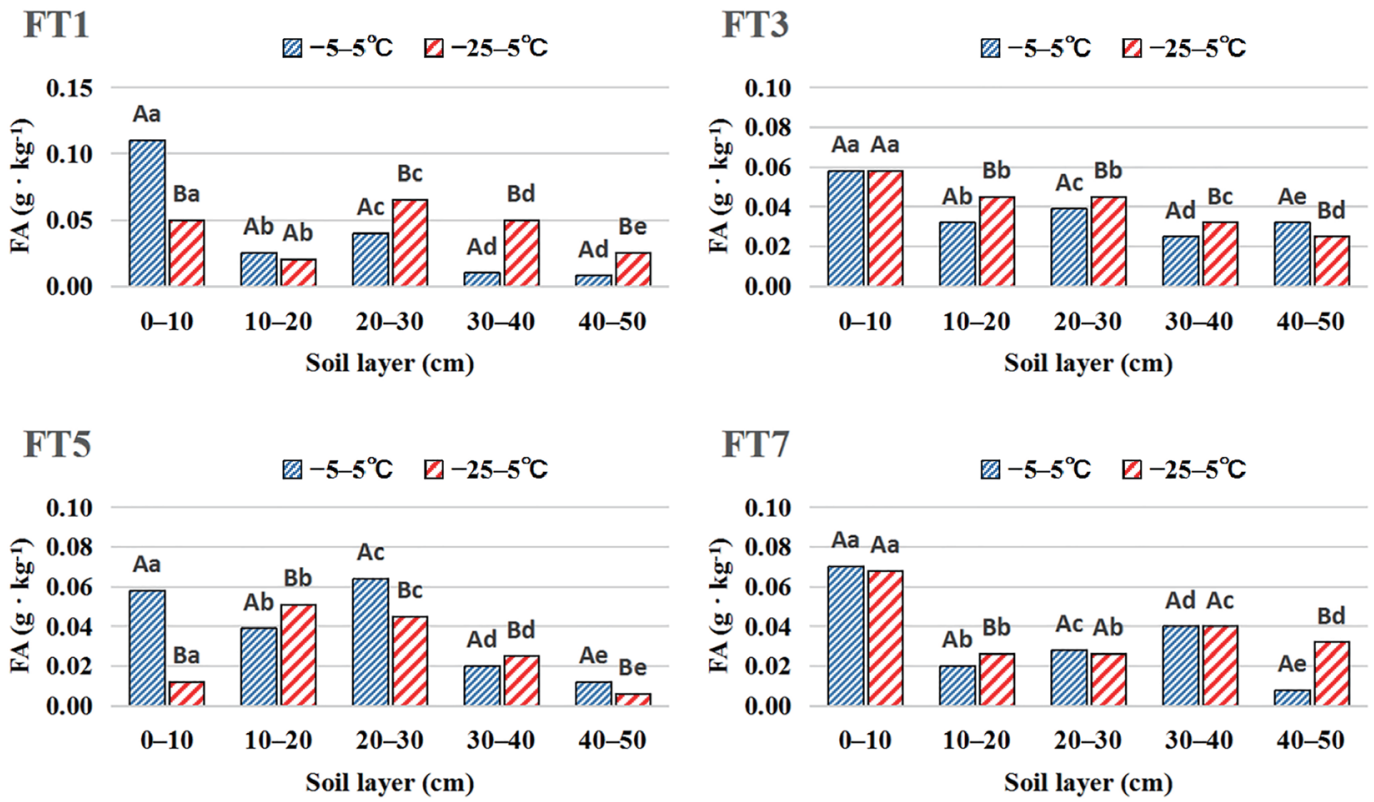

Fig. 5. (Color online) Effect of freeze-thaw temperature on FA content in saline wetland soil.

\subsubsection{Effect of freeze-thaw temperature on HA content in saline wetland soil}

Figure 6 shows the effect of the freeze-thaw temperature on the HA content in saline wetland soil. There are few studies on the effect of the freeze-thaw temperature on the HA content in saline wetland soil. As can be seen from the figure, the freeze-thaw temperature has little effect on the HA content in saline wetland soil. HA is a minor component of humus. By 

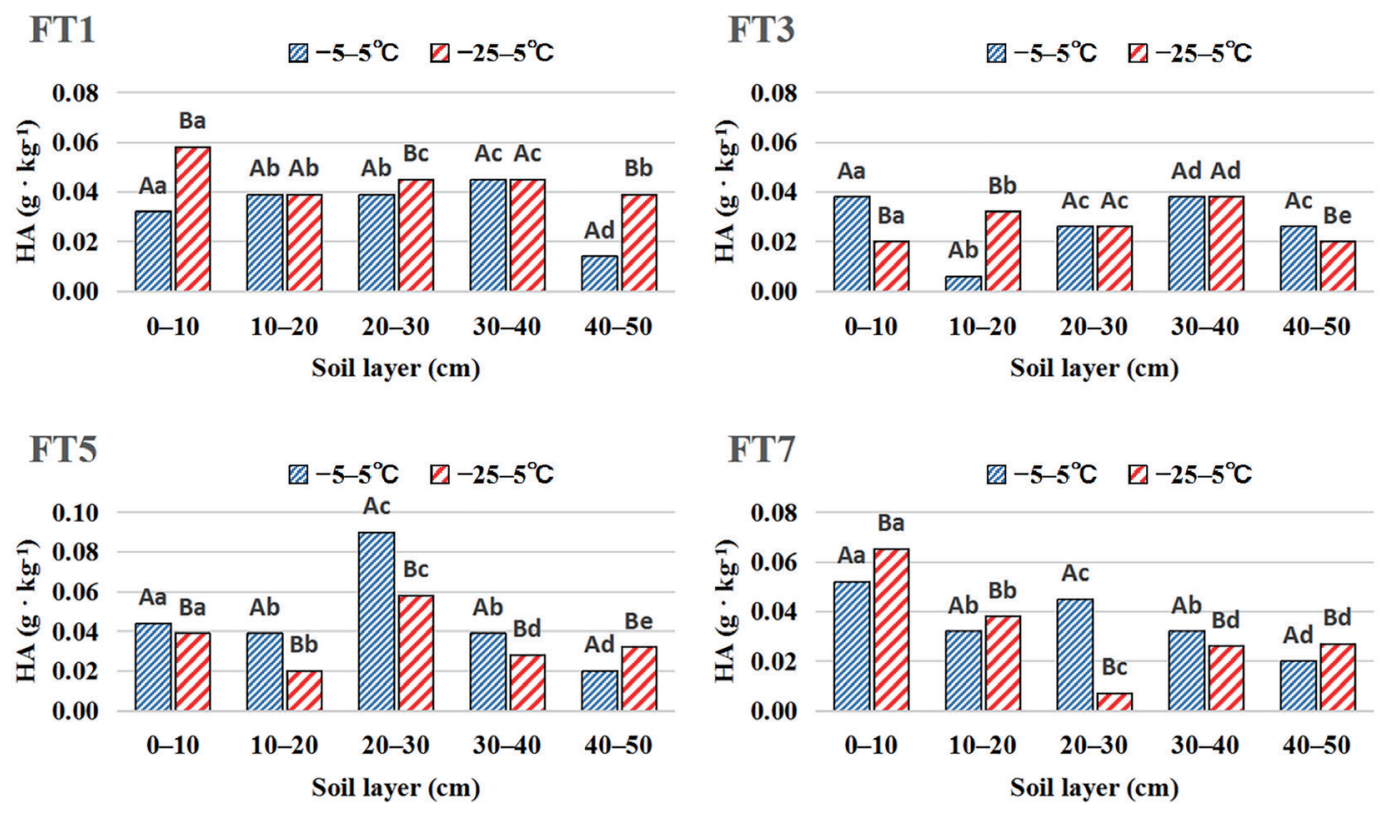

Fig. 6. (Color online) Effect of freeze-thaw temperature on HA content in saline wetland soil.

careful observation, it was found that the HA content remains unchanged after a slight increase with increasing number of freeze-thaw cycles.

\subsubsection{Effect of freeze-thaw temperature on HM content in saline wetland soil}

In the $-25-5{ }^{\circ} \mathrm{C}$ freeze-thaw cycle, the $\mathrm{HM}$ content in saline wetland soil was slightly higher than that in the $-5-5{ }^{\circ} \mathrm{C}$ freeze-thaw cycle and decreased slightly with increasing number of freeze-thaw cycles; the decrease was no more than $0.05 \mathrm{~g}$. This may be because HM is insoluble in water and has a low content in saline wetland soil (Fig. 7).

\subsection{Effects of freeze-thaw cycles on soil humus and its components}

\subsubsection{Effect of freeze-thaw cycles on humus content in saline wetland soil}

Under the condition of $-5-5{ }^{\circ} \mathrm{C}$ freeze-thaw cycles, the effects of freeze-thaw cycles on the distribution of HE in the vertical soil layers were analyzed. The results showed that after a freeze-thaw cycle, the HE content in the $0-30 \mathrm{~cm}$ soil layer decreases first and then increases, and that in the $30-50 \mathrm{~cm}$ soil layer increases first and then decreases. After one freeze-thaw cycle, the average HE content in the $0-50 \mathrm{~cm}$ soil layer is $0.33 \mathrm{~g} \cdot \mathrm{kg}^{-1}$; after three freeze-thaw cycles, the average HE content in the $0-50 \mathrm{~cm}$ soil layer is $0.17 \mathrm{~g} \cdot \mathrm{kg}^{-1}$; after five to seven freeze-thaw cycles, the average HE content in the $0-50 \mathrm{~cm}$ soil layer is $0.12 \mathrm{~g} \cdot \mathrm{kg}^{-1}$ [Fig. 8(a)]. Under the condition of $-25-5{ }^{\circ} \mathrm{C}$ freeze-thaw cycles, the effects of freeze-thaw cycles on the distribution of soil HE in vertical soil layers were analyzed. The results showed that after one freeze-thaw cycle, the average HE content in the $0-50 \mathrm{~cm}$ soil layer is $0.13 \mathrm{~g} \cdot \mathrm{kg}^{-1}$; after 


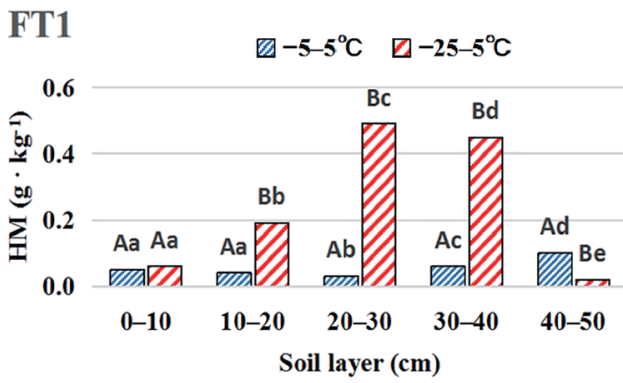

FT5

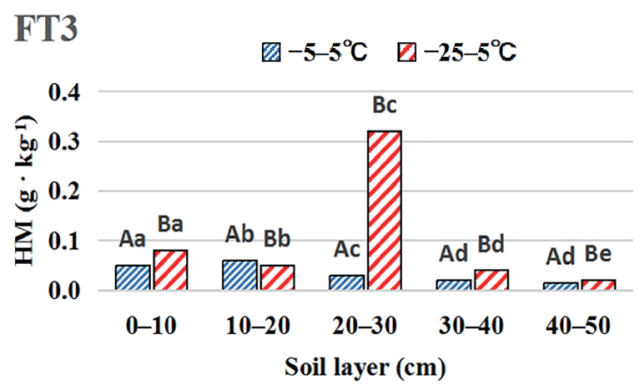

FT7
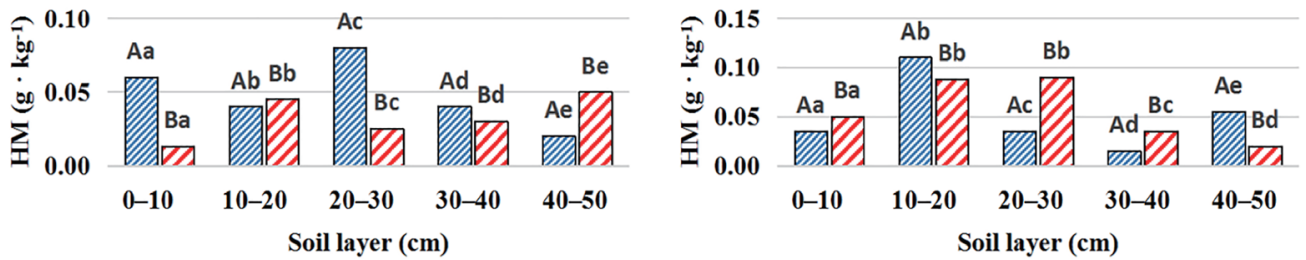

Fig. 7. (Color online) Effect of freeze-thaw temperature on the HM content in saline wetland soil.

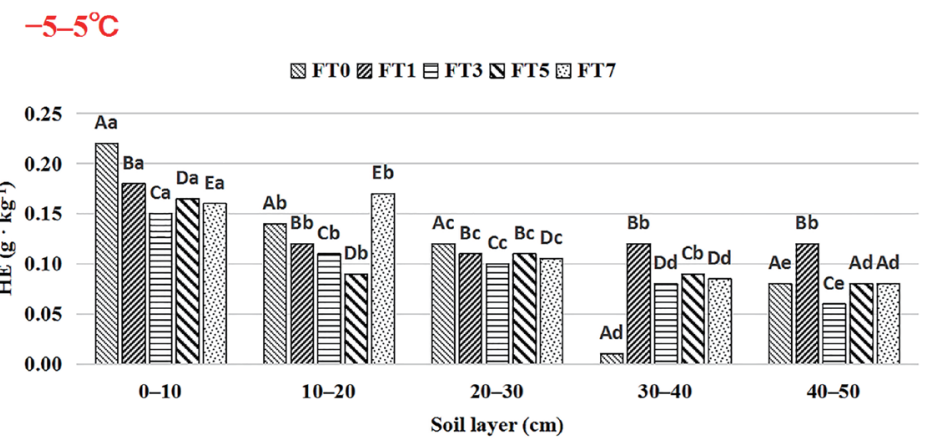

(a)

$-25-5^{\circ} \mathrm{C}$

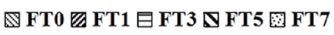

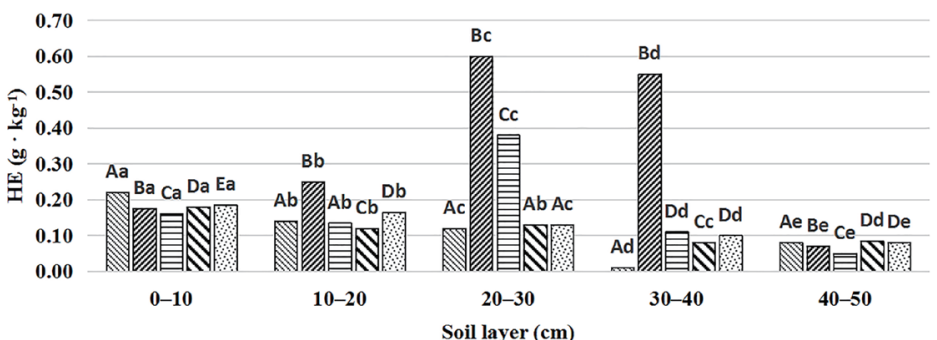

(b)

Fig. 8. (Color online) Effect of freeze-thaw cycles on HE content in saline wetland soil.

three freeze-thaw cycles, the average HE content in the $0-50 \mathrm{~cm}$ soil layer is $0.10 \mathrm{~g} \cdot \mathrm{kg}^{-1}$; after five to seven freeze-thaw cycles, the average $\mathrm{HE}$ content in the $0-50 \mathrm{~cm}$ soil layer is $0.12 \mathrm{~g} \cdot \mathrm{kg}^{-1}$ [Fig. 8(b)]. This shows that the number of freeze-thaw cycles has a significant effect on the soil HE content. The soil HE content after three freeze-thaw cycles is lower than 
that after one freeze-thaw cycle. Further negligible change in soil HE content was observed after five and seven freeze-thaw cycles. This may be because the microorganisms in the soil gradually adapted to the low-temperature environment after a few freeze-thaw cycles, resulting in the negligible change in soil HE content.

\subsubsection{Effect of freeze-thaw cycles on FA content in saline wetland soil}

At the freeze-thaw temperature of $-5-5{ }^{\circ} \mathrm{C}$, the effect of freeze-thaw cycles on the FA content in the $0-10 \mathrm{~cm}$ soil layer was analyzed, and the FA content after three freeze-thaw cycles has no significant relationship with the FA content after five freeze-thaw cycles. The effect of freeze-thaw cycles on the FA content in the 20-30 cm soil layer was analyzed, and the FA content after one freeze-thaw cycle has no significant relationship with that without freeze-thaw cycles $(p>0.05)$ [Fig. 9(a)]. At the freeze-thaw temperature of $-25-5{ }^{\circ} \mathrm{C}$, the effect of freeze-thaw cycles on the FA content in the $20-30 \mathrm{~cm}$ soil layer was analyzed, and the FA content after three freeze-thaw cycles has no significant relationship with the FA content after five freeze-thaw cycles $(p>0.05)$ [Fig. 9(b)]. The results showed that three and five freeze-thaw cycles have no clear effect on soil FA, and after seven freeze-thaw cycles, the FA content is significantly lower than that after one freeze-thaw cycle. The reason may be that the moisture content of the soil increases after multiple freeze-thaw cycles, and a higher moisture content is conducive to the accumulation of FA.

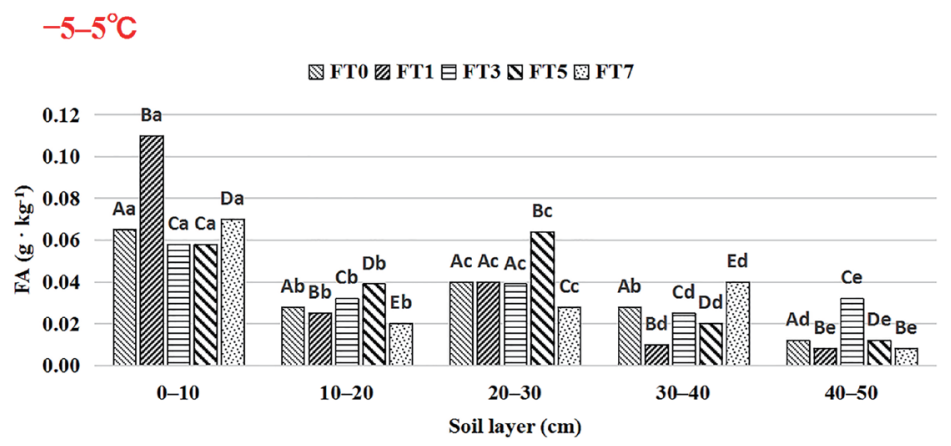

(a)

$-25-5^{\circ} \mathrm{C}$

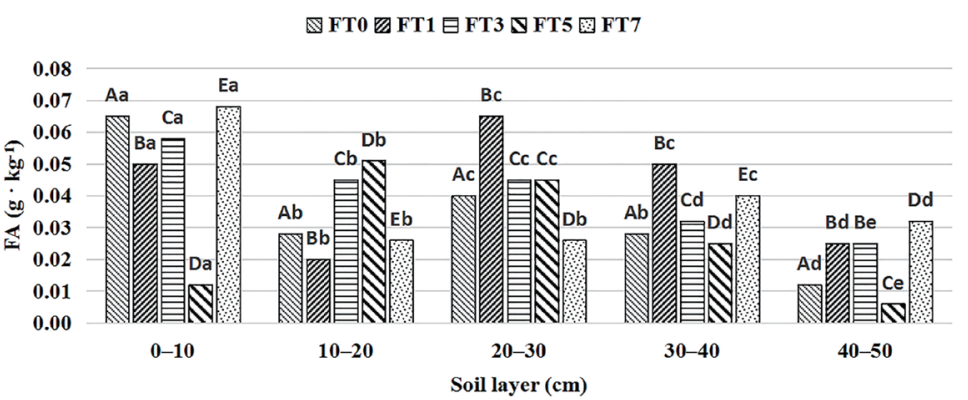

(b)

Fig. 9. (Color online) Effect of freeze-thaw cycles on FA content in saline wetland soil. 


\subsubsection{Effect of freeze-thaw cycles on HA content in saline wetland soil}

Figure 10 shows the effect of freeze-thaw cycles on the HA content. It can be seen that the HA content after five and seven freeze-thaw cycles is significantly different from that without freeze-thaw cycles. This shows that with increasing number of freeze-thaw cycles, the soil microbial activity does not completely disappear, and the remaining microorganisms decompose soil organic matter, thus affecting the HA content.

\subsubsection{Effect of freeze-thaw cycles on HM content in saline wetland soil}

Figure 11 shows the effect of freeze-thaw cycles on the HM content. Under the conditions of freeze-thaw cycles of $-5-5{ }^{\circ} \mathrm{C}$ and $-25-5{ }^{\circ} \mathrm{C}$, the effect of freeze-thaw cycles on the HM content in the vertically distributed soil layers has no clear regularity. This may be because freeze-thaw directly changes the structure of soil aggregates, breaking up large aggregates of soil into small aggregates. Thus, the soil particles that did not fully react with the solution before freeze-thaw had a higher probability of reacting with the solution after freeze-thaw, thus affecting the extraction of HM in the soil.

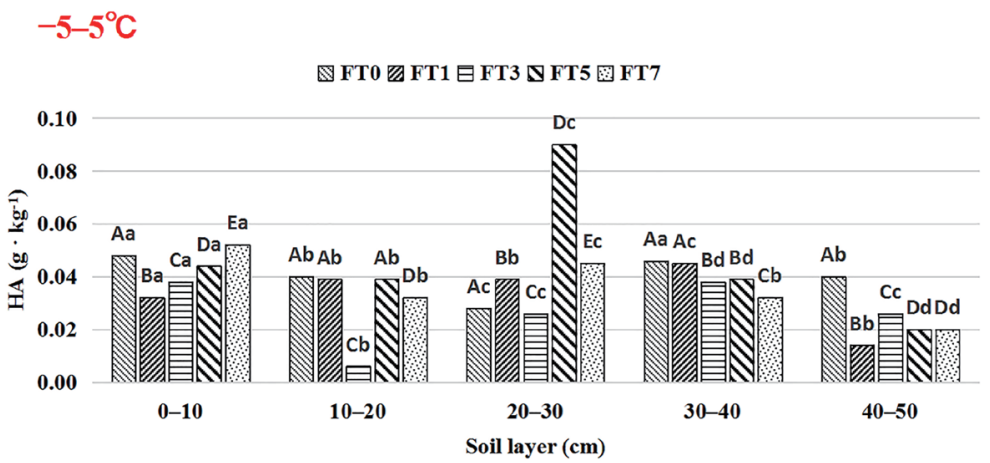

(a)

$-25-5^{\circ} \mathrm{C}$

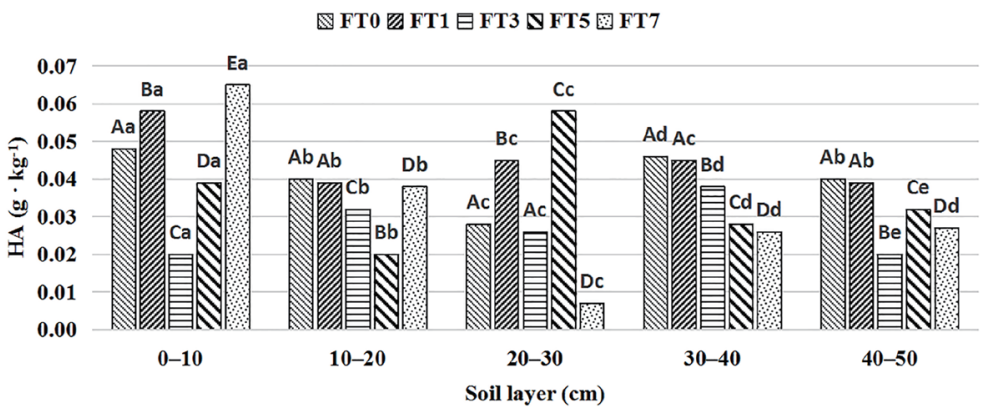

(b)

Fig. 10. (Color online) Effect of freeze-thaw cycles on HA content in saline wetland soil. 


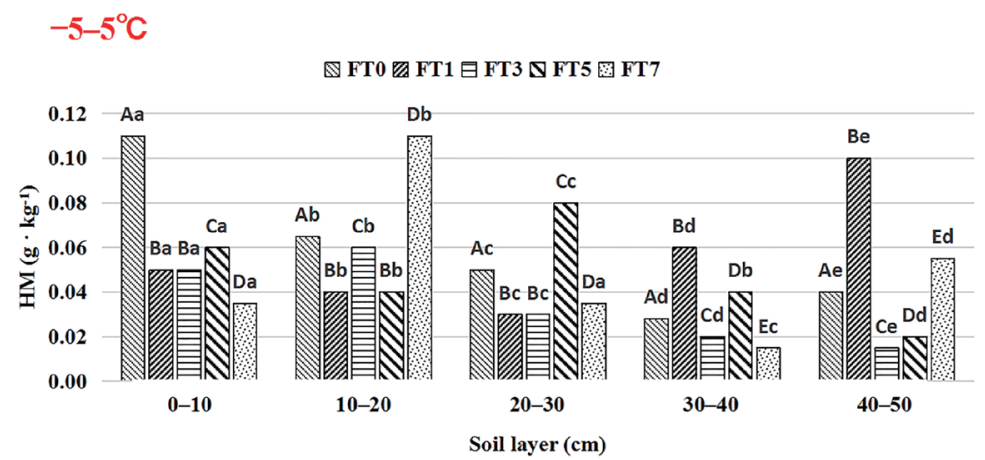

(a)

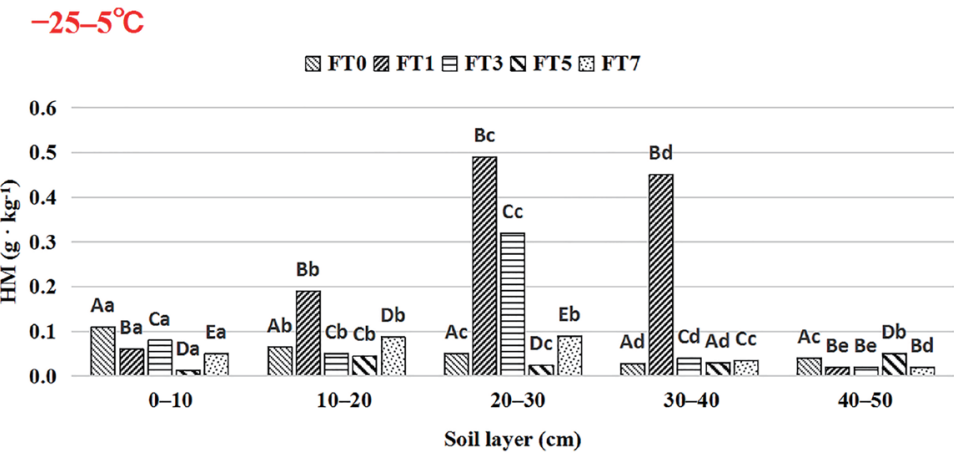

(b)

Fig. 11. (Color online) Effect of freeze-thaw cycles on HM content in saline wetland soil.

\subsection{Correlation analysis of soil humus and its components under different freeze-thaw conditions}

Under alternating freeze-thaw conditions at $-5-5{ }^{\circ} \mathrm{C}$, we saw a positive correlation between HE and FA contents in saline wetland soil; with increasing FA content in the soil, the HE content increased linearly. However, with increasing number of freeze-thaw cycles, the strength of the correlation between HE and FA contents in saline wetland soil gradually decreased (Fig. 12).

Under alternating freeze-thaw conditions at $-25-5{ }^{\circ} \mathrm{C}$, the correlation coefficient between HE and FA contents in the soil after one freeze-thaw cycle is 0.505 , that between HE and FA contents in the soil after three freeze-thaw cycles is 0.1881, that between HE and FA contents in the soil after five freeze-thaw cycles is 0.0023 , and that between HE and FA contents in the soil after seven freeze-thaw cycles is 0.2281 . With the increase in the number of freeze-thaw cycles, the correlation strength between HE and FA contents gradually decreased, and that between HE and FA contents is the highest after one freeze-thaw cycle (Fig. 13).

Under alternating freeze-thaw conditions at $-5-5{ }^{\circ} \mathrm{C}$, the correlation coefficient between HE and HA contents in the soil after one freeze-thaw cycle is 0.0027 , that between HE and HA contents in the soil after three freeze-thaw cycles is 0.0364 , that between HE and HA contents in the soil after five freeze-thaw cycles is 0.1052 , and that between HE and HA contents in the 

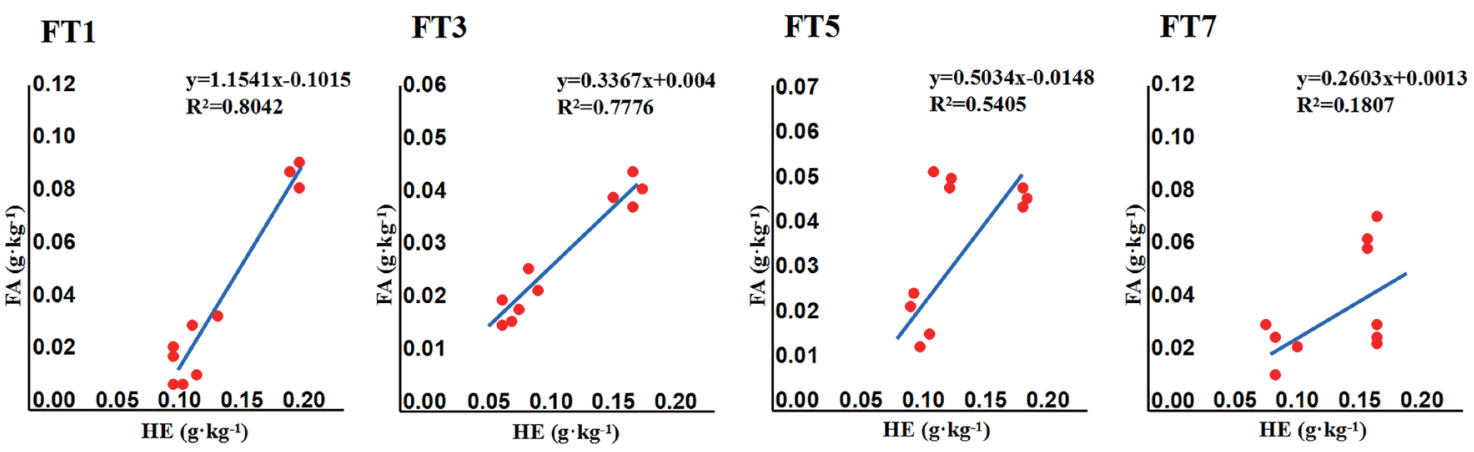

Fig. 12. (Color online) Correlation between FA and HE contents under different freeze-thaw cycles at $-5-5^{\circ} \mathrm{C}$.
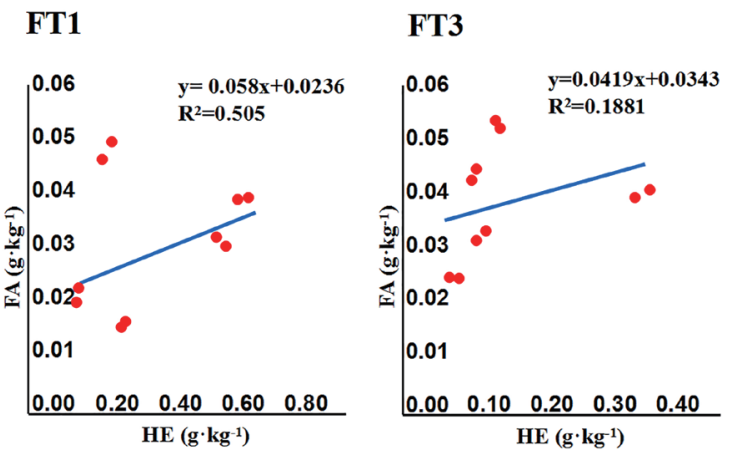

FT5

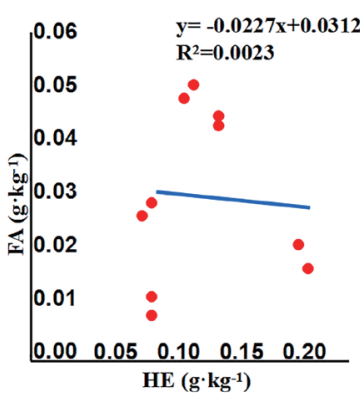

FT7

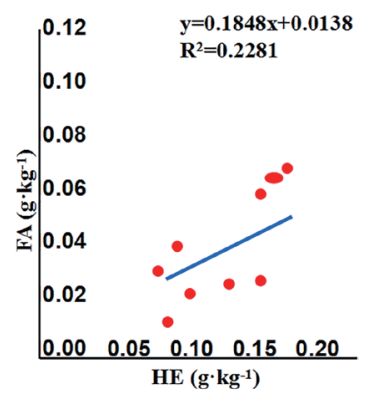

Fig. 13. (Color online) Correlation between FA and HE contents under different freeze-thaw cycles at $-25-5{ }^{\circ} \mathrm{C}$.

soil after seven freeze-thaw cycles is 0.2519 . With the increase in the number of freeze-thaw cycles, the correlation strength between HE and HA contents gradually increased, and that between HE and HA contents is the highest after seven freeze-thaw cycles (Fig. 14).

Under alternating freeze-thaw conditions at $-25-5^{\circ} \mathrm{C}$, the HE content in saline wetland soil was positively correlated with the HA content, that is, the HE content increased linearly with the HA content in the soil. With increasing number of freeze-thaw cycles, the strength of the correlation between HE and HA contents in saline wetland soil gradually increased (Fig. 15).

Under alternating freeze-thaw conditions at $-5-5{ }^{\circ} \mathrm{C}$, with the increase in the number of freeze-thaw cycles, the correlation strength between HE and HM contents first increased and then decreased. The correlation strength between HE and HM contents is the highest after three freeze-thaw cycles, and that between HE and HM contents in the soil after three freeze-thaw cycles is 0.5862 (Fig. 16).

Under alternating freeze-thaw conditions at $-25-5{ }^{\circ} \mathrm{C}$, the correlation coefficient between HE and HM contents in the soil after one freeze-thaw cycle is 0.9913 , that between HE and HM contents in the soil after three freeze-thaw cycles is 0.9902, that between HE and HM contents in the soil after five freeze-thaw cycles is 0.6905 , and that between HE and HM contents in the soil after seven freeze-thaw cycles is 0.0825 . With the increase in the number of freeze-thaw cycles, the correlation strength between HE and HM contents gradually decreased (Fig. 17). 

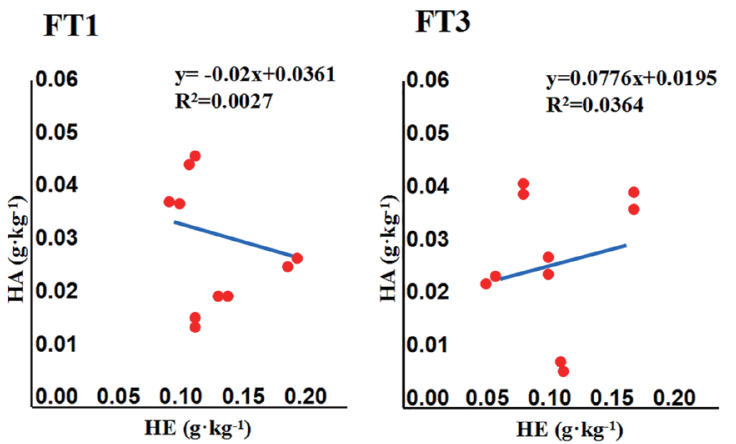

FT5

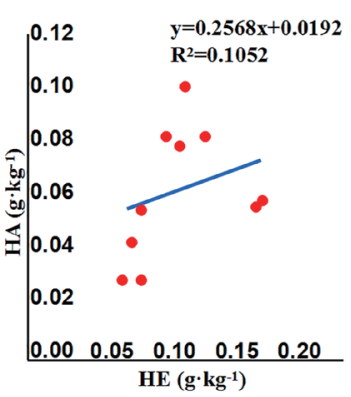

FT7

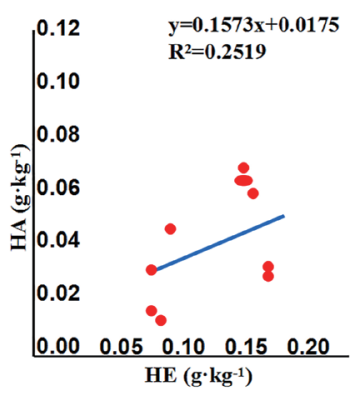

Fig. 14. (Color online) Correlation between HA and HE contents under different freeze-thaw cycles at $-5-5^{\circ} \mathrm{C}$.

FT1

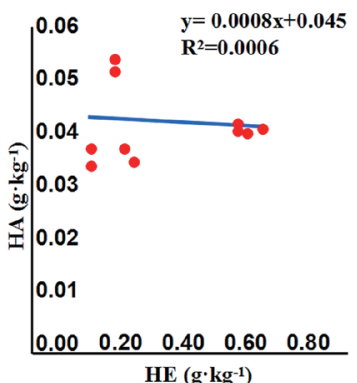

FT3

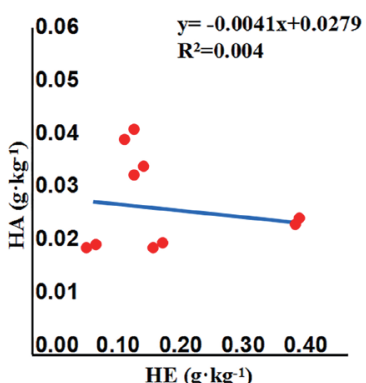

FT5

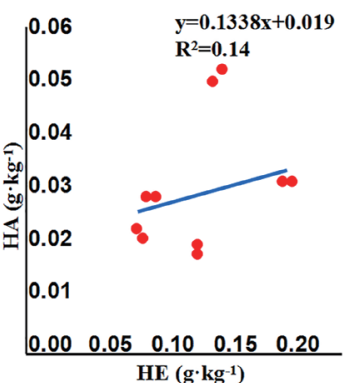

FT7

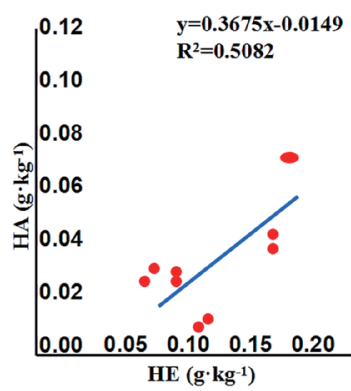

Fig. 15. (Color online) Correlation between HA and HE contents under different freeze-thaw cycles at $-25-5{ }^{\circ} \mathrm{C}$.
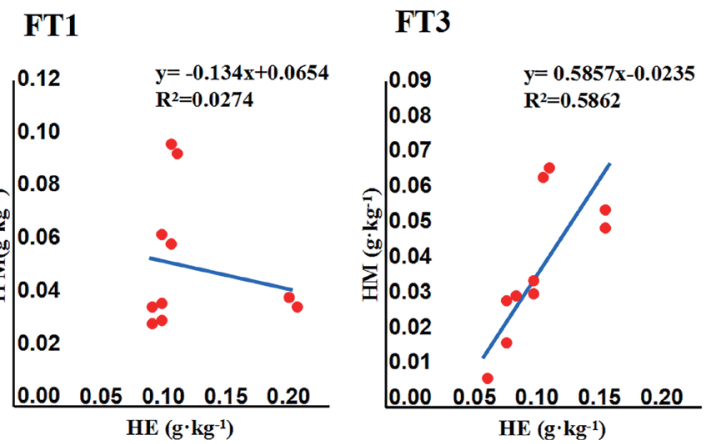

FT5

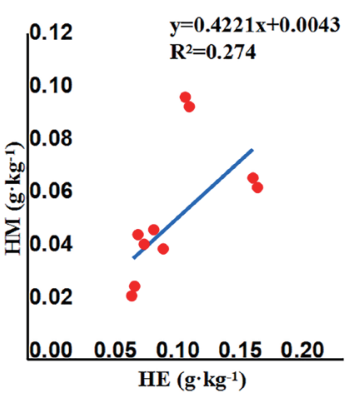

FT7

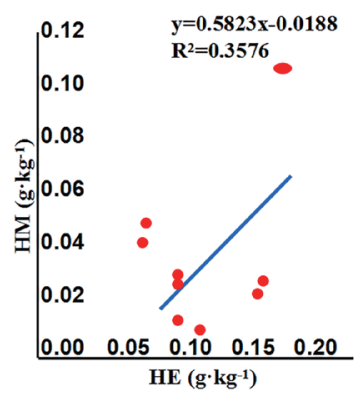

Fig. 16. (Color online) Correlation between HM and HE contents under different freeze-thaw cycles at $-5-5^{\circ} \mathrm{C}$.

FT1

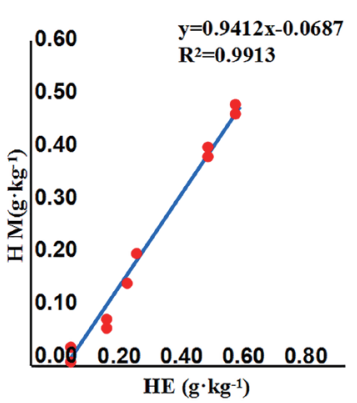

FT3

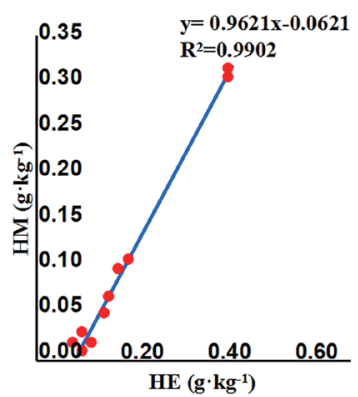

FT5

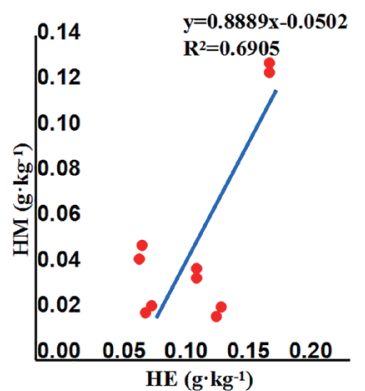

FT7

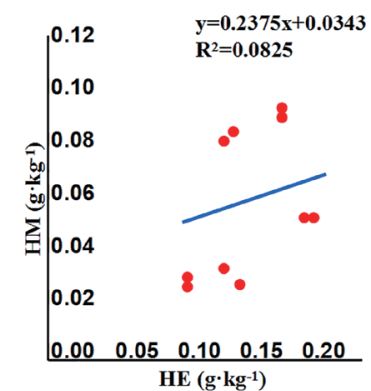

Fig. 17. (Color online) Correlation between $\mathrm{HM}$ and $\mathrm{HE}$ contents under different freeze-thaw cycles at $-25-5{ }^{\circ} \mathrm{C}$. 


\subsection{Comparison with previous studies}

Most scholars have studied the changes in the physical and chemical properties of the soil in the freeze-thaw process indoors through laboratory simulation experiments, which is different from the process occurring in the field. As a result, conclusions in different studies cannot be unified or may even contradict each other owing to different experimental conditions. ${ }^{(35)}$ Therefore, research on the mechanism of soil freeze-thaw under accurately monitored conditions is a key point in the future. In this study, the temperature sensor is used to determine the freezing and thawing temperatures, and all events are monitored in real time. Compared with those in previous studies, the effect of the freeze-thaw cycles on soil humus is explained more effectively by the freeze-thaw simulation culture experiment using the temperature sensor.

Thus far, research on the effect of freeze-thaw on humus has been limited to black and forest soils, and there has been no research on the response of humus to freeze-thaw cycles. ${ }^{(36)}$ The results of this study fill this gap.

In addition, research on the mechanism of freeze-thaw has mainly focused on the physical and chemical properties of soil, hydrothermal conditions, carbon and nitrogen conversion, and so on. ${ }^{(37)}$ The change in humus composition in soil was analyzed from two aspects in this study: the freeze-thaw temperature and the number of freeze-thaw cycles. The results can be used to explain the effects of the freeze-thaw mechanism on soil properties.

\section{Discussion}

In this study, we used a temperature sensor to control the freeze-thaw temperature, combined with field monitoring and laboratory culture experiments, and analyzed the effects of the freeze-thaw temperature and the number of freeze-thaw on the soil humus in saline alkali wetlands (Table 1). It can be seen from Table 2 that in terms of soil freeze-thaw research, previous studies mainly focused on black soil and forest soil, and determined that the freeze-

Table 1

Comparison with other freeze-thaw studies.

\begin{tabular}{lcccc}
\hline Comparison & $\begin{array}{c}\text { Freeze-thaw of } \\
\text { saline wetland }\end{array}$ & $\begin{array}{c}\text { Effect of } \\
\text { freeze-thaw on } \\
\text { humus }\end{array}$ & $\begin{array}{c}\text { The temperature sensor is } \\
\text { used to determine the } \\
\text { freeze-thaw temperatures. }\end{array}$ & $\begin{array}{c}\text { Field monitoring and } \\
\text { laboratory simulation }\end{array}$ \\
\hline $\begin{array}{l}\text { Other studies } \\
\text { This paper }\end{array}$ & $\mathrm{N}$ & $\mathrm{N}$ & $\mathrm{N}$ & $\mathrm{N}$ \\
\hline
\end{tabular}

Table 2

Comparison with other freeze-thaw studies.

\begin{tabular}{lcc}
\hline Comparison & This research paper & Other studies \\
\hline Research area & Saline wetland, special soil type & Songnen plain black soil, forest soil \\
\hline Research content & Soil humus components (HE, HA, FA, and HM) & Single \\
Research technology & $\begin{array}{c}\text { The temperature sensor is used to determine } \\
\text { the freeze-thaw temperatures, } \\
\text { and all events are monitored in real time. }\end{array}$ & Laboratory simulation \\
\hline
\end{tabular}


thaw cycle has a direct impact on the changes of soil carbon and nitrogen. ${ }^{(38-40)}$ Humus is a relatively stable carbon component in the soil carbon pool, and the changes under the effect of freeze-thaw can better explain the effect of freeze-thaw on the stability of soil carbon pool. In this study, the use of temperature sensors to monitor the changes in freeze-thaw temperature makes the research data more referable.

Soil humus is a polymer compound produced by soil organic matter in the process of decomposition. Changes in its quantity affect the stability of soil organic carbon. ${ }^{(41)}$ The results of this study indicate that significant differences exist between soils with different freeze-thaw cycle temperatures. In frequent freeze-thaw cycles, the humification process of soil changes dynamically. In the 20-40 cm soil layer, humus and its components have clear changes, while other soil layers have no clear regular pattern, because the decayed matter of plant litter is mainly distributed in the $20-40 \mathrm{~cm}$ soil layer. Therefore, the change in humus composition in the $20-40 \mathrm{~cm}$ soil layer is discussed.

Under the freeze-thaw cycles of $-5-5{ }^{\circ} \mathrm{C}$, the soil HE content decreased with increasing number of freeze-thaw cycles, and under the freeze-thaw cycles of $-25-5{ }^{\circ} \mathrm{C}$, the soil $\mathrm{HE}$ content increased first and then decreased. The increase in HE content in the $20-40 \mathrm{~cm}$ soil layer under short-term freeze-thaw cycles is consistent with that reported by Li et al. ${ }^{(42)}$ In the early stage of a freeze-thaw cycle, soil surface humus accumulates rapidly. In the later stage of a freeze-thaw cycle, the humification process is inhibited. The results show that readily decomposable substances such as sugars and starches in soil litter can be decomposed rapidly under the effect of the temperature change, which provides numerous nutrients for soil microorganisms and increases their activity; the formation of humic substances mainly depends on the polymerization of microorganisms, ${ }^{(43)}$ so the ability of microorganisms to synthesize humic substances is enhanced. This suggests that even frequent freeze-thaw cycles do not inhibit microbial activity, consistent with the findings of Morley et al. and Schadt et al. ${ }^{(44,45)}$ With increasing freeze-thaw frequency, refractory substances gradually accumulate and the decomposition rate decreases. Thus, the rate of humic substance synthesis in soil becomes less than its decomposition rate, and the degree of soil humification begins to decrease and becomes stable, which is different from the mechanism proposed in previous studies on black and forest soils. ${ }^{(46,47)}$

HA and FA are important indicators to explain the degree of soil humification. ${ }^{(48)}$ The degree of soil humification has a certain impact on the stability of soil organic carbon. With increasing culture time, frequent freeze-thaw cycles, and a strong freezing action, the structure of refractory materials in soil is destroyed and the decomposability is improved; therefore, the frequency of freeze-thaw has a significant impact on the degree of soil humification. ${ }^{(49)}$ Through the analysis of different freeze-thaw temperatures, the results show that the HA content of the 20-40 cm soil layer decreases first and then increases under short-term freeze-thaw alternation, and the HA content becomes stable after repeated freeze-thaw alternation, and its change is similar to that in HE content. After alternate freezing and thawing, the HA and FA contents decreased gradually, and their contents in soil after freeze-thaw were lower than those in soil without freeze-thaw. This indicates that the frequency of freeze-thaw has different effects on the degree of soil humification at different freeze-thaw temperatures. 
With increasing freeze-thaw frequency and freeze-thaw temperatures of $-25-5{ }^{\circ} \mathrm{C}$, the soil is more apt to form acidic humus, which is unfavorable for the growth and reproduction of the soil biological community, ${ }^{(50)}$ thus inhibiting soil humification. Frequent freeze-thaw cycles may destroy the unstable humus structure in the early stage and finally lead to reduced soil humification. ${ }^{(51)}$ Compared with the frequency of freeze-thaw cycles, the effect of temperature on soil humification is more significant. This may be due to the major differences in the response mechanisms of different microbial communities to freezing and thawing conditions, which may also be an important mechanism for wetland ecosystem maintenance.

\section{Conclusion}

By using a temperature sensor, the freeze-thaw temperature was monitored accurately in real time, and the data showing the response of the soil humus component to temperature were obtained.

(1) With increasing number of freeze-thaw cycles, the HE content in saline wetland soil tended to first decrease and then slowly increase to a stable value. Under the condition of $-5-5{ }^{\circ} \mathrm{C}$ freeze-thaw cycles, after one to three freeze-thaw cycles, the average $\mathrm{HE}$ content in the $0-50 \mathrm{~cm}$ soil layer decreased by $0.16 \mathrm{~g} \cdot \mathrm{kg}^{-1}$. Under the condition of $-25-5^{\circ} \mathrm{C}$ freeze-thaw cycles, after one to three freeze-thaw cycles, the average HE content in the $0-50 \mathrm{~cm}$ soil layer decreased by $0.03 \mathrm{~g} \cdot \mathrm{kg}^{-1}$. The decrease in FA content with increasing number of freeze-thaw cycles was small. Changes in the humus composition of the $20-40 \mathrm{~cm}$ soil layer were clearly observed.

(2) Under frequent freeze-thaw cycles, the humification process of soil changes dynamically. In this experiment, under the alternating freeze-thaw conditions of $-25-5{ }^{\circ} \mathrm{C}$, the $\mathrm{HE}$ and HM contents in soil showed a significant correlation.

\section{Acknowledgments}

This work was partially sponsored by the Changchun University Scientific Research and Cultivation Fund (No. 2019JBC27L40) and the National Natural Science Foundation of China (Nos. 51179073 and 41471152).

\section{References}

1 T. H. Wang, S. X. Meng, and G. S. Cui: China Res. Comp. Util. 37 (2019) 1. https://doi.org/10.3969/ j.issn.1008-9500.2019.01.030

2 P. Grogan, A. Michelsen, and P. Ambusl: Soil. Biol. Biochem. 36 (2004) 4. https://doi.org/10.1016/ j.soilbio.2003.12.007

3 P. M. Groffman, C. T. Driscoll, and T. J. Fahey: Biogeochemistry 56 (2001) 2. https://doi.org/10.2307/1469925

4 H. C. Zhao, X. Wei, Y. He, and T. Chinese: J. Soil. Water. Conserv. 32 (2018) 5. https://doi.org/10.13870/j.cnki. stbcxb.2018.05.013

5 H. Li: Hydro. Sci. Cold. Zone. Eng. 2 (2019) 1 (in Chinese). https://doi.org/10.3969/j.issn.1002-3305.2019.01.015

6 M. T. Wang and Y. R. Wang: Ecol. Env. Sci. 19 (2010) 12. https://doi.org/10.3969/j.issn.1674-5906.2010.12.017

7 X. Y. Liu, R. J. Bian, and H. F. Lu: Proc. Chinese. Aca. Sci. 2 (2018) 13. https://doi.org/184-190.doi:10.16418/ j.issn.1000-3045.2018.02.008. 
8 L. J. Li, J. G. Xia, and G. K. Yan: J. Soil. Water. Cons. 32 (2018) 4. https://doi.org/10.13870/j.cnki. stbcxb.2018.04.026

9 X. Liu, S. Dou, and C. L. Li: Acta. Ped. Sin. 53 (2016) 1. https://doi.org/10.11766/trxb201503160014.

10 Y. Gao, X. Zeng, and Q. Xie: Water. Air. Soil. Pollut. 226 (2015) 233. https://doi.org/10.1007/s11270-015-24792

11 Y. C. Luo, Y. L. Lv, and H. Yang: J. Ecol. Env. 11 (2014) 66. https://doi.org/10.3969/j.issn.1674-5906.2014.11.008

12 F. Wang, Y. Zhu, and S. Chen: J. Agricul. Eng. 24 (2014) 53. https://doi.org/10.3969/j.issn.1002-6819.2013.24.016

13 M. Gao, Y. X. Li, X. L. Zhang, F. X. Zhang, P. Liu, S. P. Gao, and X. C. Chen: J. Agri. Env. Sci. 12 (2016) 2269. https://doi.org/10.11654/jaes.2016-1087

14 Z. Chen, S. Q. Yang, Q. W. Zhang, H. K. Zhou, X. Jing, A. P Zhang, D. Y. Han, and Z. L. Yang: J. Ecol. 4 (2016) 1083. https://doi.org/10.5846/stxb201406061171

15 Y. Li, H. Zhu, and X. Yuan: Acta. Pedologica. Sinica 51 (2014) 5. https://doi.org/10.11766/trxb201312240610

16 X. X. Lv, H. Y. Sun, J. K. Wang, and X. L. Ding: J. Soil. Sci. 47 (2016) 5. https://doi.org/10.19336/j.cnki. trtb.2016.05.37

17 Q. X. Li, J. X. Guo, X. H. Zhou, Y. He, Y. N. Liu, B. Xu, and G. M. Zhao: J. Nanjing. Agri. Uni. 42 (2019) 6. https://doi.org/10.7685/jnau.201901047

18 L. Li, G. M. Xin, Y. M. Du, G. J. Zhu, H. Yi, S. Gao, and M. J. Fu: Chinese J. Soil. Sci. 50 (2019) 3. https://doi. org/10.19336/j.cnki.trtb.2019.03.17

19 K. H. Yao, L. Xiao, P. Li, and Y. Gao: J. Soil. Water. Conserv. 34 (2020) 3. https://doi.org/10.13870/j.cnki. stbcxb.2020.03.039

20 H. O. Zhang, J. C. Xie, and H. P. Nan: J. Soil. Water. Conserv. 30 (2016) 3. https://doi.org/10.13870/j.cnki. stbcxb.2016.03.047

21 J. Tang, Y. Q. Liu, and S. N. Wang: J. Soil. Water. Conserv. 33 (2019) 2. https://doi.org/10.13870/j.cnki. stbcxb.2019.02.026

22 Q. Liu, J. Tang, J. J. Wang, and Y. K. Qu: J. Northeast. Agri. Uni. 22 (2018) 9. https://doi.org/10.19720/j.cnki. issn.1005-9369.2018.09.006

23 S. H. Jia, W. W. Wang, and R. S. Zhang: J. Soil. Water. Conserv. 31 (2017) 6. https://doi.org/10.13870/j.cnki. stbcxb.2017.06.031

24 H. R. Zhang, F. H. Li, and W. Lv: Trans. Chinese. Societ. Agri. Eng. 33 (2017) 3. https://doi.org/10.11975/ j.issn.1002-6819.2017.03.017

25 H. X. Ou, J. C. Jiang, and H. P. Nan: J. Soil. Water. Conserv. 30 (2016) 3. https://doi.org/10.13870/j.cnki. stbcxb.2016.03.047

26 G. Y. Zhao, D. N. Zhao, and S. Jiang: Acta. Ecologica. Sinica 37 (2017) 16. https://doi.org/10.5846/ stxb201605170953

27 Y. Wang, J. S. Liu, and Q. Y. Wang: Ecol. Env. Sci. 7 (2013) 1269. https://doi.org/10.3969/ j.issn.1674-5906.2013.07.030

28 Y. Zhao, W. M. Zhou, and S. L. Wang: J. Ecol. 36 (2017) 6. https://doi.org/10.13292/j.1000-4890.201706.021

29 Y. Gao, X. Zeng, and Q. Xie: Water. Air. Soil. Poll. 226 (2015) 223. https://doi.org/10.1007/s11270-015-2479-2

30 L. X. Chen and C. D. Yang: J. Forest. Sci. 43 (2007) 1. https://doi.org/10.3321/j.issn:1001-7488.2007.02.002

31 Y. A. Dang, S. Q. Li, and G. D. Wang: J. Ecol. 32 (2012) 6. https://doi.org/10.5846/stxb201102110162

32 N. Wang and C. K. Wang: Appl. Ecol. 8 (2019) 1120. https://doi.org/10.13287/j.1001-9332.201908.040

33 M. Pédrot, A. Dia, and M. Davranche: J. Coll. Interf. Sci. 34 (2010) 5. https://doi.org/10.1016/j.jcis.2010.01.069

34 Y. H. Kong, L. F. Zhu, and A. A. Wu: Appl. Ecol. 9 (2019) 346. https://doi.org/10.13287/j.1001-9332.201909.005

35 E. H. Wang, Y. S. Zhao, and X. Y. Xia: Acta Ecologica Sinica 34 (2014) 21. https://doi.org/10.5846/ stxb201307031829

36 G. N. Zhang, X. J. Lin, and Y. M. Li: Spectrosc. Spectral Anal. 38 (2018) 4. https://doi.org/10.3964/j.is sn.1000-0593(2018)04-1298-05

37 H. W. Ran, J. H. Fan, and J. Huang: Pratacultural Sci. 36 (2019) 4. https://doi.org/10.11829/ j.issn.1001-0629.2019-0035

38 G. J. Jia, Y. B. Zhou, L. M. Dai, and W. M. Zhou: Ecol. Env. Sci. 21 (2014) 4. https://doi.org/10.3969/ j.issn.1674-5906.2012.04.006

39 Y. H. Juan, Y. Liu, and L. Gong: Jiangsu. Agri. Sci. 47 (2019) 21. https://doi.org/36.10.15889/ j.issn.1002-1302.2019.21.068

40 C. Ge, W. Lu, and G. Y. Wei: Ecol. Env. Sci. 28 (2019) 12. https://doi.org/10.16258/j.cnki.1674-5906.2019.12.005

41 C. X. Wang, P. F. Dong, and K. L. Dang: J. Northwest. Uni. 48 (2020) 4. https://doi.org/10.13207/j.cnki. jnwafu.2020.04.010

42 L. H. Li, X. Li, and M. Xu: Jiangsu. Agri. Sci. 4 (2014) 708. https://doi.org/10.15889/j.issn.1002-1302.2015.04.114 
43 B. Y. Sun, Z. B. Li, J. B. Xiao, Y. T. Zhang, B. Ma, J. M. Li, and D. B. Chen: Appl. Ecol. 1 (2019) 26. https:// doi.org/10.13287/j.1001-9332.201901.019.

44 C. R. Morley, J. A. Trofymow, and D. C. Coleman: Mic. Ecol. 9 (1983) 34. https://doi.org/4.10.1007/bf02019022

45 C. W. Schadt, A. P. Martin, D. A. Lipson, and S. K. Schmidt: Science 301 (2003) 5638. https://doi.org/10.1126/ science. 1086940

46 H. Sun, J. H. Qian, and Y. Wu: Soils 4 (2008) 1123. https://doi.org/10.3321/j.issn:0253-9829.2008.04.001

47 X. Y. Wei, Y. L. Yang, and F. Z. Wu: J. Appl. Ecol. 30 (2019) 7. https://doi.org/10.13287/j.1001-9332.201907.006

48 Y. A. Dang, S. Q. Li, and G. D. Wang: J. Ecol. 6 (2012) 36. https://doi.org/1820-1829.doi:10.5846/ stxb201102110162.

49 S. L. Pang and Q. Liu: Acta. Ecologica. Sinica. 9 (2002) 22. https://doi.org/10.3321/j.issn:1000-0933.2002.09.024

50 D. T. Song, J. J. Li, and J. H. Nie: Ecol. Env. 2 (2008) 563. https://doi.org/722-726.doi:10.3969/ j.issn.1674-5906.2008.02.054

51 W. H. Li, A. M. Li, and S. C. Zhang: Env. Chem. 4 (2008) 325. https://doi.org/503-506.doi:10.3321/ j.issn:0254-6108.2008.04.020

\section{About the Authors}

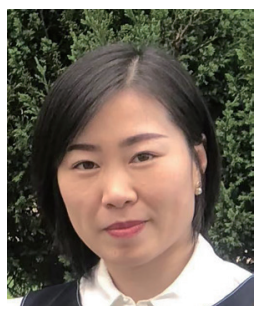

Qian Liu received her B.S. and M.S. degree in 2006 and 2009, respectively, from Yanbian University, China. At present, she is studying in the field of environmental science at Jilin University while working as a lecturer at Changchun University. Her research interests are in soil organic carbon cycles and resource utilization. (hamiqi.365@163.com)

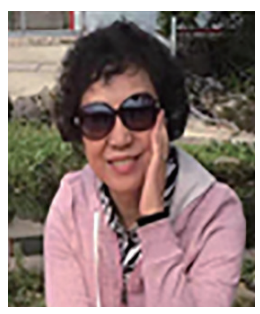

Jie Tang received her B.S. degree from Jilin University, China, in 1982 and her M.S. and Ph.D. degrees from the College of Environment and Resources, China, in 1988 and 1997, respectively. She was a professor at Jilin University, China. (tangjie0724@126.com)

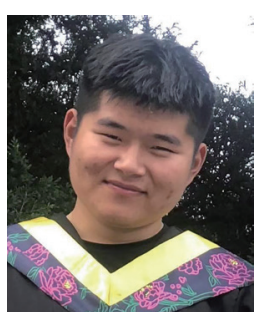

Cheng-shuai He received his B.S. degree from Changchun University, China, in 2019. At present, he is studying for a master's degree at Henan Institute of Science and Technology. His research field is environmental resources utilization. (52605501@qq.com)

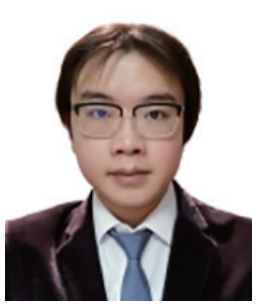

Christopher Chun Ki Chan has worked with IBM Markham Research Lab and Microsoft Lab in Seattle on data warehousing for DB2 and mobile messaging. He has submitted a patent on real-time BASH debugging. He has also worked with the Government of Ontario, Superior Court of Ontario, on automated rule-based scheduling. He was a contract lecturer of data science at Ryerson University and a sessional instructor of computer architecture at University of Ontario Institute of Technology. (christopher.c.chan@ryerson.ca) 